\title{
Effect of acetic acid feeding on the circadian changes in glycogen and metabolites of glucose and lipid in liver and skeletal muscle of rats
}

\author{
Takashi Fushimi ${ }^{1}$ and Yuzo Sato ${ }^{2}$ \\ ${ }^{1}$ Central Research Institute, Mizkan Group Corporation, 2-6 Nakamura-cho, Handa, Aichi 475-8585, Japan \\ ${ }^{2}$ Department of Health Science, Faculty of Psychological and Physical Sciences, Aichi Gakuin University, Nisshin, Japan
}

(Received 12 November 2004 - Revised 9 June 2005 - Accepted 13 June 2005)

\begin{abstract}
The aim of the present study is to investigate the effect of acetic acid feeding on the circadian changes in glycogen concentration in liver and skeletal muscle. Rats were provided meal once daily (09.00-13.00 hours) for $10 \mathrm{~d}$. On the 11th day, they were either killed immediately or given $9 \mathrm{~g}$ diet containing either 0 (control) or $0.7 \mathrm{~g} / \mathrm{kg}$-diet acetic acid beginning at 09.00 hours for $4 \mathrm{~h}$, as in the previous regimen. Rats in the fed group were killed at 4,8 or $24 \mathrm{~h}$ after the start of feeding. At $4 \mathrm{~h}$ after the start of feeding, the acetic acid group had significantly greater liver and gastrocnemius muscle glycogen concentrations $(P<0.05)$. Also, at this same point, liver xylulose-5-phosphate, a key stimulator of glycolysis, the ratio of fructose-1,6-bisphosphate to fructose-6phosphate in skeletal muscle, which reflects phosphofructokinase-1 activity, and liver malonyl-CoA, an allosteric inhibitor of carnitine palmitoyl-transferase, were significantly lower in the acetic acid group than in the control group $(P<0.05)$. In addition, the acetic acid group had a significantly lower serum lactate concentration and lower ratio of insulin to glucagon than the control group at the same point $(P<0.05)$. We conclude that a diet containing acetic acid may enhance glycogen repletion but not induce supercompensation, a large increase in the glycogen level that is beneficial in improving performance, in liver and skeletal muscle by transitory inhibition of glycolysis. Further, we indicate the possibility of a transient enhancement of fatty acid oxidation in liver by acetic acid feeding.
\end{abstract}

Acetic acid: Glycogen repletion: Glycolysis: Fatty acid oxidation

Acetic acid is the main component of vinegar. While vinegar is frequently used as seasoning, it also has been used traditionally as folk medicine, having effects such as improving appetite, enhancing mineral absorption and speeding recovery from fatigue. Fatigue, when defined physiologically as loss of ability for power output, is caused by the depletion of glycogen used as fuel in skeletal muscle or as a carbohydrate source in liver to maintain the blood glucose level. Recently, we demonstrated that acetic acid feeding with carbohydrate enhanced glycogen repletion after exercise or food deprivation at dietary concentrations (Fushimi et al. 2001, 2002). Further, the intake of a diet containing $2 \mathrm{~g}$ acetic acid/ $\mathrm{kg}$ diet, a concentration corresponding to food prepared with vinegar, after food deprivation induced this effect due to the inhibition of glycolysis in liver and skeletal muscle (Fushimi et al. 2001). Under postprandial conditions, glycogen content in liver and skeletal muscle reaches a maximum from 4 to $8 \mathrm{~h}$ after the start of feeding (Holness et al. 1988; Carnona et al. 1991). A large increase in glycogen concentration above the level found in the well-fed sedentary state is termed 'glycogen supercompensation', and is beneficial in postponing fatigue and improving performance (Holloszy et al. 1998). If the effect of acetic acid could be maintained over several hours, it could be assumed that acetic acid feeding would lead to glycogen supercompensation. However, the degree of durability of the effects of acetic acid is unknown because we have only shown the efficacy of acetic acid feeding at $2 \mathrm{~h}$ after feeding.

Administration of fatty acid leads to inhibition of glucose metabolism, called the glucose-sparing effect (Williamson \& Krebs, 1961; Struck \& Ashmore 1966; Ross \& Krebs, 1967). SCFA, including acetic acid, have been reported to have the same effect in hepatocytes (Kawaguchi et al. 2002). We showed that the inhibition of glycolysis by acetic acid feeding after food deprivation was caused by down regulation of phosphofructokinase-1 in liver and skeletal muscle (Fushimi et al. 2001). Thus, acetic acid feeding is supposed to restrict glucose utilization, in other words, to enhance fatty acid utilization by those tissues.

Here, to investigate the possibility that acetic acid feeding results in glycogen supercompensation and enhancement of fatty acid utilization, we studied circadian changes in concentrations of glycogen and metabolites of glucose and lipid in liver and skeletal muscle after acetic acid feeding using meal-fed rats. Vinegar for consumer use mainly contains acetic acid at a concentration of 3-9\% (Ren et al. 1997). Foods such as sushi and marinated meats, vegetables and fish that are prepared with vinegar contain a maximum of $60 \mathrm{~g} / \mathrm{kg}$ acetic acid (Mine et al. 1982; Rodger et al. 1984; Fujii

Abbreviations: F-1,6- $\mathrm{P}_{2}$, fructose 1,6-bisphosphate; F-2,6- $\mathrm{P}_{2}$, fructose 2,6-bisphosphate; F-6-P, fructose 6-phosphate; GS, glycogen synthetase; HMG-CoA, 3-hydroxy-3methylglutaryl-CoA; I/G, ratio of insulin to glucagon; PFK-2/F26Bpase, the bifunctional enzyme, phosphofructokinase-2 and fructose-2,6-bisphosphatase; X-5-P, xylulose 5phosphate.

*Corresponding author: Dr Takashi Fushimi, fax +81 56924 5028, email tfushimi@mizkan.co.jp 
et al. 1992; Seus \& Martin, 1993; Chang et al. 1994). In Japan, an average of 20 different food items per day are eaten (Okuda \& Hayashi, 1994; Shimbo et al. 1994; Kasamatsu et al. 1996). Thus, in the present study, by assuming that one food item prepared with vinegar is eaten once per day, we used a diet containing $0.7 \mathrm{~g}$ acetic acid/kg diet, which is an approximate 20 -fold diluted value of $15 \mathrm{~g} / \mathrm{kg}$ corresponding to a marinated food.

\section{Materials and methods}

\section{Animals, feeding protocol and diets}

Five-week-old male rats (Sprague-Dawley; Japan NBR, Hashima, Japan) weighing $120 \pm 2 \mathrm{~g}$ were individually housed in a temperature-controlled room $\left(24 \pm 1^{\circ} \mathrm{C}\right)$ with a $12 \mathrm{~h}$ light-dark cycle. The light period began at 06.00 hours. The animals had free access to water and were allowed access to a powdered commercial non-purified diet (MF; Oriental Yeast Co., Tokyo, Japan) once daily (from 09.00 to 13.00 hours) for $10 \mathrm{~d}$ after which they were divided into seven groups of five rats each, all with the same mean body weight $(120 \pm 2 \mathrm{~g})$. The animals were cared for in accordance with the Guidelines for Animal Experimentation established at the 34th Annual Meeting of the Japanese Association for Laboratory Animal Science (22 May 1987).

The powdered experimental diet, based on the AIN-76 formula, contained $63.4 \mathrm{~g}$ glucose $/ 100 \mathrm{~g}$ diet and 0 or $0.07 \mathrm{~g}$ acetic acid/ $100 \mathrm{~g}$ diet instead of cornstarch and sucrose (designated as control group diet or acetic acid group diet, respectively).

After a $20 \mathrm{~h}$ period of food deprivation, the experiments commenced at 09.00 hours (defined as $0 \mathrm{~h}$ ). At $0 \mathrm{~h}$, one group of rats was killed without being given any diet (designated as 0 -time group), and the remaining six groups were each given $9 \mathrm{~g}$ of the appropriate experimental diet, to which they had access for $4 \mathrm{~h}$. The fed rats were decapitated 4,8 and $24 \mathrm{~h}$ after the start of feeding (defined as 4,8 and $24 \mathrm{~h}$, respectively). There were no differences in food intake for the first $2 \mathrm{~h}$ and the total of $4 \mathrm{~h}$ (7.14 (SD 0.42) and 8.94 (SD 0.02) g, respectively) and in total energy intake per g body weight (1.22 (SD 0.02$) \mathrm{kJ} / \mathrm{g}$ ) between the fed groups. Serum, liver, gastrocnemius muscles (comprising fast-twitch and slow-twitch fibres), soleus muscles (comprising mainly slow-twitch fibres) and stomach were collected immediately. Gut contents in the 0-time group and the fed groups (control group and acetic acid group) at $24 \mathrm{~h}$ were below $0.4 \mathrm{~g}$ and there were no differences in gut contents between the fed groups at 4 or $8 \mathrm{~h}(12.3$ (SD 0.4) and 8.5 (SD 0.7) g, respectively). Liver and muscles were freeze-clamped in liquid $\mathrm{N}_{2}$ immediately after decapitation and stored at $-80^{\circ} \mathrm{C}$ until assay. However, two cases were exceptional; it took about $4 \mathrm{~min}$ to remove liver in one 0 -time group animal and about $8 \mathrm{~min}$ to excise soleus muscle in one control group animal at $24 \mathrm{~h}$.

\section{Determinations of liver and skeletal muscle metabolites}

Glycogen concentrations were measured by Lo's method (Lo et al. 1970). Glucose 6-phosphate, fructose 6-phosphate (F-6-P) and fructose 1,6-bisphosphate $\left(\mathrm{F}-1,6-\mathrm{P}_{2}\right)$ were measured by the spectrophotometrical method (Lowry \& Passonneau, 1972). Xylulose 5-phosphate (X-5-P), citrate and fructose 2,6-bisphosphate (F-2, 6- $\mathrm{P}_{2}$ ) were determined as previously described (Casazza \& Veech, 1986; Dagley, 1974; Kuwajima et al. 1984, respectively).
cAMP was measured by an enzyme immunoassay kit (Direct Cyclic AMP; Assay Designs, Ann Arbor, MI, USA). Malonyl-CoA and 3-hydroxy-3-methylglutaryl-CoA (HMG-CoA) were determined by a previously reported HPLC method (DeBuysere \& Olson, 1983) with a slight modification. In brief, mobile-phase solvents were (solvent A): $0.2 \mathrm{M}$-sodium phosphate, $1 \%$ chloroform (v/v), pH 5.0; and (solvent B): $0.2 \mathrm{M}$-sodium phosphate, $49 \%$ methanol, $1 \%$ chloroform $(\mathrm{v} / \mathrm{v}), \mathrm{pH} 5 \cdot 0$. The percentage of solvent B was $12 \%$ at time- $0,16 \%$ at $8 \mathrm{~min}, 26 \%$ at $14 \mathrm{~min}, 40 \%$ at $20 \mathrm{~min}$ and $90 \%$ at $32 \mathrm{~min}$, rising in a linear manner. After the final composition of solvent B reached $90 \%$, it was held for 3 min and the initial condition was re-established for $10 \mathrm{~min}$ in a linear manner. This composition was kept for $10 \mathrm{~min}$ additionally, and then the column was ready for the next injection.

\section{Measurements of serum metabolites and hormones}

Serum glucose and NEFA were measured by colorimetry with individual assay kits (Glucose C II test Wako and NEFA C-test Wako, respectively; Wako Pure Chemicals, Osaka, Japan). Serum insulin and glucagon were assayed by ELISA kits (Ultra Sensitive Rat Insulin ELISA Kit (Morinaga Bioscience, Kanagawa, Japan) and Rat Glucagon ELISA Kit Wako (Wako Pure Chemicals), respectively). Serum acetate was determined by capillary GC (Murase et al. 1995). Blood pyruvate and lactate were measured by colorimetry with individual assay kits (F-kit Pyruvate and F-kit Lactate; Roche Diagnostics, Mannheim, Germany, respectively).

\section{Enzymatic analysis}

Glycogen synthetase (GS) activity was measured fluorometrically as the ratio of form I GS, which is independent of glucose 6-phosphate activation, to total enzyme activity (Passonneau \& Lowry, 1993).

\section{Statistical analysis}

Data are expressed as mean values with their standard errors for five different rats per group. The data were analysed using comparisons between the 0 -time group and fed groups at various time-points after the start of feeding or between two fed groups at the same point. Homogeneity of variance was evaluated by Levene's test. Statistical evaluations of the results with homogeneous variances or heterogeneous variances were performed by the two-tailed unpaired Student's $t$ test or Mann-Whitney test, respectively. Differences with $P<0.05$ were considered to be significant. SPSS for Windows version 10.0 J (SPSS, Chicago, IL, USA) was used for all analyses.

\section{Results}

Glycogen concentrations in liver and gastrocnemius and soleus muscles

At 4 and 8 h, liver (Fig. 1(A)) and skeletal muscle (Fig. 1(B, C)) glycogen concentrations in the fed groups were significantly higher than in the 0-time group. Further, at $4 \mathrm{~h}$, the acetic acid group had significantly higher glycogen concentrations in liver and gastrocnemius muscle than the control group. At the same time-point, in soleus muscle, the glycogen concentration in the acetic acid group was $30 \%$ greater than that in the control group $(P<0 \cdot 1)$. However, there were no significant differences 

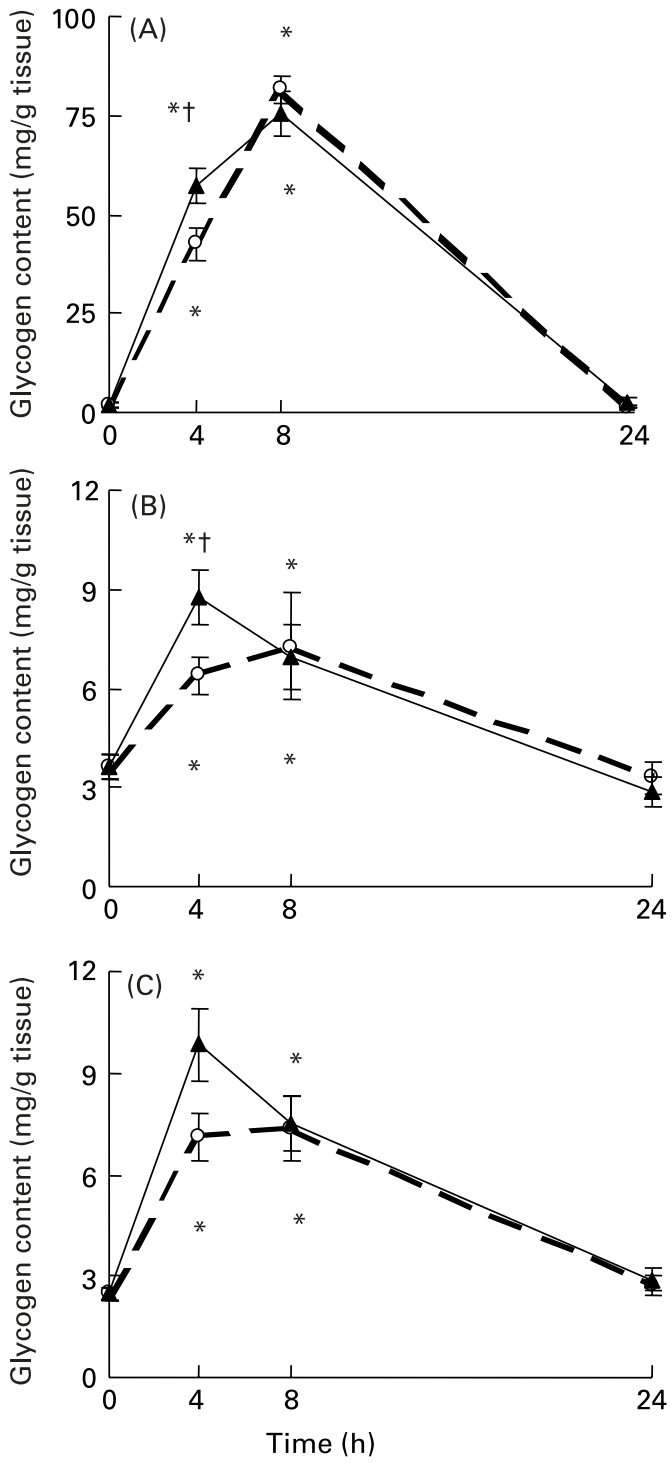

Fig. 1. Circadian change in glycogen concentrations in liver (A), gastrocnemius muscle (B) and soleus muscle (C) in rats fed diets with and without acetic acid. Values are means with their standard errors shown by vertical bars (five rats per group). Rats were killed before, or 4,8 or $24 \mathrm{~h}$ after the start of consuming a diet containing $0.07 \mathrm{~g}$ acetic acid $/ 100 \mathrm{~g}$ diet $(\mathbf{\Lambda})$ or a diet without acetic acid $(\mathrm{O}$, control). For details of procedures, see p. 715 . *Mean values were significantly different from those at 0 -time $(P<0.05)$. †Mean values were significantly different from those of control group at the same time-point $(P<0.05)$.

between the fed groups in any tissue at the other time-points. The maximum glycogen concentrations did not differ significantly between fed groups in the following circumstances: in liver at $8 \mathrm{~h}$ in both groups, in gastrocnemius muscle at $8 \mathrm{~h}$ in the control group $v$. at $4 \mathrm{~h}$ in the acetic acid group, and in soleus muscle at $8 \mathrm{~h}$ in the control group $v$. at $4 \mathrm{~h}$ in the acetic acid group.

\section{Concentrations of serum metabolites and hormones}

Serum lactate concentrations (Table 1) and the insulin-glucagon ratio in the acetic acid group were lower than in the control group at $4 \mathrm{~h}$. At $8 \mathrm{~h}$, the serum lactate concentration was the same as at $4 \mathrm{~h}$. However, there were no significant differences in serum glucose, insulin, glucagon and NEFA values and blood pyruvate concentrations between the fed groups at any time-point (data not shown). Compared with the 0-time group, the fed groups had significantly higher serum insulin, blood pyruvate and lactate values, with the exception of the acetic acid group at $8 \mathrm{~h}$, and significantly lower serum NEFA concentrations at 4 and $8 \mathrm{~h}$.

\section{Concentrations of metabolites and enzyme activity in liver}

$\mathrm{X}-5-\mathrm{P}$ and malonyl-CoA concentrations in the acetic acid group were significantly lower than in the control group at $4 \mathrm{~h}$ (Table 2). The acetic acid group had lower F-2,6- $\mathrm{P}_{2}$ and HMGCoA and higher cAMP concentrations at the same time-point and a lower malonyl-CoA level at $8 \mathrm{~h}$ than the control group $(P<0 \cdot 1)$. Citrate concentration and GS activity did not differ between the fed groups at any time-point (data not shown). Compared with the 0-time group, the fed groups had significantly higher malonyl-CoA and HMG-CoA concentrations at 4 and $8 \mathrm{~h}$. The concentration of cAMP in the control group at 4 and $8 \mathrm{~h}$ was significantly lower than in the 0 -time group.

\section{Concentrations of metabolites, the ratio of fructose 1,6-bisphosphate to fructose 6-phosphate and enzyme activity in skeletal muscle}

The F-1,6-P2 F-6-P ratios in the acetic acid group were significantly lower in both gastrocnemius and soleus (Table 3) muscles than in the control group at $4 \mathrm{~h}$. However, there were no significant differences in glucose 6-phosphate, F-6-P, F-1,6- $\mathrm{P}_{2}$, citrate and malonyl-CoA concentrations and GS activity in skeletal muscle between the fed groups at any time-point (data not shown).

\section{Discussion}

The acetic acid group had higher glycogen concentrations in liver and skeletal muscles than the control group at $4 \mathrm{~h}$ (Fig. 1). However, there were no significant differences in maximum glycogen content in any tissue between the fed groups. Hence, we have confirmed that a diet containing acetic acid enhances glycogen repletion, but does not induce glycogen supercompensation, which is a large increase in glycogen concentration above the level found in the well-fed sedentary state, in the liver and skeletal muscles of rats.

The fed groups consumed about $80 \%$ of food provided by $2 \mathrm{~h}$ after the start of feeding (7.14 (SD 0.42) g/9 g given). Neither the rate of intake nor the gut content differed significantly between the fed groups at 2 and $4 \mathrm{~h}$, indicating that at least dietary acetic acid did not enhance glucose absorption. Acetate administered orally to human subjects was shown to be absorbed and metabolized within $1.5 \mathrm{~h}$ (Pomare et al. 1985). As the mean concentration of serum acetate at $4 \mathrm{~h}$ in the acetic acid group was about $20 \%$ greater than that in the control group without a significant difference between the fed groups, it seems likely that the absorbed acetate had been metabolized in the acetic acid-fed groups immediately and therefore was not noted at $4 \mathrm{~h}$. Thus, this might explain why there were no significant differences in citrate concentrations between the fed groups in liver and skeletal muscle at any time-point.

In the present study, at $4 \mathrm{~h}$, the acetic acid group had a significantly lower X-5-P level than the control group $(P<0 \cdot 05)$ (Table 2). Also, cAMP in the acetic acid group was $10 \%$ greater than in the control group $(P<0 \cdot 1)$. The present results are consistent with a previous report on perfused acetic acid into liver (Liu \& Uyeda, 1996). Seitz et al. (1976) reported that cAMP in 
Table 1. Changes in blood lactate and the ratio of serum insulin to glucagon (I/G) in rats fed diets with or without acetic acid $^{*}$

(Mean values with their standard errors for five rats per group)

\begin{tabular}{|c|c|c|c|c|c|c|c|c|}
\hline \multirow[b]{3}{*}{ Type of diet } & \multicolumn{8}{|c|}{ Time after start of feeding (h) } \\
\hline & \multicolumn{2}{|c|}{0} & \multicolumn{2}{|c|}{4} & \multicolumn{2}{|c|}{8} & \multicolumn{2}{|c|}{24} \\
\hline & Mean & SEM & Mean & SEM & Mean & SEM & Mean & SEM \\
\hline \multicolumn{9}{|c|}{ Blood lactate (mmol/l) } \\
\hline Control & 0.94 & 0.18 & $2.78 \dagger$ & 0.43 & $1.79 \dagger$ & 0.15 & 0.96 & 0.02 \\
\hline Acetic acid & & & $1.57 \dagger$ & $0 \cdot 16$ & $1.35 \ddagger$ & 0.12 & 1.35 & 0.33 \\
\hline \multicolumn{9}{|l|}{$\mathrm{I} / \mathrm{G}$} \\
\hline Control & $6 \cdot 78$ & 0.81 & $9.68 \dagger$ & 0.20 & 9.52 & 1.46 & 7.57 & 0.71 \\
\hline Acetic acid & & & $8.35 \ddagger$ & 0.36 & $9.65 \dagger$ & 0.69 & $7 \cdot 37$ & 0.39 \\
\hline
\end{tabular}

${ }^{*}$ Rats were killed before, or 4,8 or $24 \mathrm{~h}$ after the start of consuming a diet containing $0.07 \mathrm{~g}$ acetic acid $/ 100 \mathrm{~g}$ diet (acetic acid group) or a diet without acetic acid (control group). For details of procedures, see p. 715 .

$\dagger$ Mean values were significantly different from those at 0 -time $(P<0.05)$.

$\ddagger$ Mean values were significantly different from those of the control group at the same time-point $(P<0.05)$.

liver was regulated by serum I/G under a starvation-refeeding condition. In our study, the acetic acid group had a significantly lower I/G at the same time-point (Table 1). X-5-P and cAMP regulate dephosphorylation and phosphorylation of the bifunctional enzyme, phosphofructokinase-2 and fructose-2,6-bisphosphatase (PFK-2/F26Bpase) in liver through X-5-P-activated protein phosphatase $2 \mathrm{~A}$ and cAMP-dependent protein kinase, respectively (El-Maghrabi et al. 1982; Nishimura \& Uyeda, 1995). PFK-2/F26Bpase controls F-2,6- $\mathrm{P}_{2}$ synthesis by both dephosphorylation, a synthesis form, and phosphorylation, a degradation form. At $4 \mathrm{~h}$ the concentration of $\mathrm{F}-2,6-\mathrm{P}_{2}$ in liver, a potent regulator of gluconeogenesis and glycolysis (see reviews by Uyeda et al. 1982; Claus et al. 1984; Hers \& Van Schaftingen, 1984), in the acetic acid group was $40 \%$ lower than that in the control group $(P<0 \cdot 1$; Table 2$)$ and lower than $5 \mathrm{nmol} / \mathrm{g}$, the activating concentration for glycolysis (Hue et al. 1984). Therefore, at $4 \mathrm{~h}$ in the acetic acid group, the inhibition of glycolysis and the activation of gluconeogenesis in liver might have been induced via lower $\mathrm{F}-2,6-\mathrm{P}_{2}$ due to the increase in the phosphorylated state of PFK-2/F26Bpase through the lower $\mathrm{X}-5-\mathrm{P}$ and higher cAMP.

In both gastrocnemius and soleus muscles, at $4 \mathrm{~h}$, the acetic acid group had significantly lower F-1,6- $\mathrm{P}_{2}-\mathrm{F}-6-\mathrm{P}$ ratios, which reflects the activity of phosphofructokinase-1, a potent regulator of glycolysis (Wakelam \& Pette, 1982), than the control group (Table 3). Further, in addition to the lower F-2,6- $\mathrm{P}_{2}$ level in liver, the suppression of the postprandial increase of blood lactate in the acetic acid group at $4 \mathrm{~h}$ might be assumed to result from both the activation of gluconeogenesis in liver and the inhibition of glycolysis in skeletal muscle.

The pathway of glycogen synthesis is via gluconeogenesis (indirect pathway) and via a glucose transport/phosphorylation step (direct pathway) (McGarry et al. 1987). Thus, the mechanism of enhancement of glycogen repletion is considered to be through

Table 2. Changes in liver metabolites in rats fed diets with or without acetic acid*

(Mean values with their standard errors for five rats per group)

\begin{tabular}{|c|c|c|c|c|c|c|c|c|}
\hline \multirow[b]{3}{*}{ Type of diet } & \multicolumn{8}{|c|}{ Time after start of feeding $(\mathrm{h})$} \\
\hline & \multicolumn{2}{|c|}{0} & \multicolumn{2}{|c|}{4} & \multicolumn{2}{|c|}{8} & \multicolumn{2}{|c|}{24} \\
\hline & Mean & SEM & Mean & SEM & Mean & SEM & Mean & SEM \\
\hline \multicolumn{9}{|l|}{ X-5-P $(\mathrm{nmol} / \mathrm{g})$} \\
\hline Control & $19 \cdot 5$ & $6 \cdot 0$ & 33.4 & $2 \cdot 8$ & $21 \cdot 0$ & $2 \cdot 6$ & $12 \cdot 6$ & $3 \cdot 0$ \\
\hline Acetic acid & & & $23.6 \ddagger$ & $2 \cdot 7$ & $19 \cdot 7$ & $3 \cdot 1$ & $11 \cdot 5$ & $2 \cdot 6$ \\
\hline \multicolumn{9}{|c|}{ cAMP (nmol/g) } \\
\hline Control & 0.51 & 0.03 & $0.41 \dagger$ & 0.01 & $0.39 \dagger$ & 0.01 & 0.52 & 0.02 \\
\hline Acetic acid & & & 0.47 & 0.03 & 0.44 & 0.05 & 0.55 & 0.01 \\
\hline \multicolumn{9}{|c|}{$\mathrm{F}-2,6-\mathrm{P}_{2}(\mathrm{nmol} / \mathrm{g})$} \\
\hline Control & 1.53 & 0.42 & 5.73† & $1 \cdot 15$ & $4 \cdot 32$ & $1 \cdot 33$ & 1.69 & 0.12 \\
\hline Acetic acid & & & 3.06 & 0.76 & $6 \cdot 00 \dagger$ & 1.58 & 1.67 & 0.21 \\
\hline \multicolumn{9}{|c|}{ Malonyl-CoA (nmol/g) } \\
\hline Control & $2 \cdot 0$ & 0.2 & $10 \cdot 2 \dagger$ & 1.4 & $5.0 \dagger$ & 0.2 & $2 \cdot 1$ & 0.3 \\
\hline Acetic acid & & & 6.6†‡ & 0.4 & $4.4 \dagger$ & 0.2 & $2 \cdot 1$ & $0 \cdot 1$ \\
\hline \multicolumn{9}{|c|}{ HMG-CoA (nmol/g) } \\
\hline Control & $2 \cdot 78$ & 0.20 & $8.56 \dagger$ & 1.00 & $6 \cdot 24 \dagger$ & 0.40 & 3.19 & 0.13 \\
\hline Acetic acid & & & $6 \cdot 22 \dagger$ & 0.66 & $5.81 \dagger$ & 0.64 & 2.69 & 0.27 \\
\hline
\end{tabular}

F-2,6- $\mathrm{P}_{2}$, fructose-2,6-bisphosphate; HMG-CoA, 3-hydroxy-3-methylglutaryl-CoA; X-5-P, xylulose-5-phosphate.

${ }^{*}$ Rats were killed before, or 4,8 or $24 \mathrm{~h}$ after the start of consuming a diet containing $0.07 \mathrm{~g}$ acetic acid $/ 100 \mathrm{~g}$ diet (acetic acid group) or a diet without acetic acid (control group). For details of procedures, see p. 715 .

$\dagger$ Mean values were significantly different from those at 0 -time $(P<0.05)$.

$\ddagger$ Mean values were significantly different from those of the control group at the same time-point $(P<0.05)$. 
Table 3. Changes in the ratio of fructose-1,6-bisphosphate to fructose-6-phosphate in skeletal muscle of rats fed diets with or without acetic acid*

(Mean values with their standard errors for five rats per group)

\begin{tabular}{|c|c|c|c|c|c|c|c|c|}
\hline \multirow[b]{3}{*}{ Type of diet } & \multicolumn{8}{|c|}{ Time after start of feeding (h) } \\
\hline & \multicolumn{2}{|c|}{0} & \multicolumn{2}{|c|}{4} & \multicolumn{2}{|c|}{8} & \multicolumn{2}{|c|}{24} \\
\hline & Mean & SEM & Mean & SEM & Mean & SEM & Mean & SEM \\
\hline \multicolumn{9}{|l|}{ Gastrocnemius } \\
\hline Control & 0.55 & 0.12 & 1.22 & 0.34 & 0.76 & 0.15 & 0.78 & 0.15 \\
\hline Acetic acid & & & $0.48 \dagger$ & 0.06 & 0.65 & 0.08 & 0.64 & 0.20 \\
\hline \multicolumn{9}{|l|}{ Soleus } \\
\hline Control & 0.87 & 0.28 & 0.98 & 0.11 & 1.07 & 0.21 & 0.81 & 0.17 \\
\hline Acetic acid & & & $0.62 \dagger$ & 0.08 & 0.91 & 0.14 & 0.99 & 0.14 \\
\hline
\end{tabular}

${ }^{*}$ Rats were killed before, or 4,8 or $24 \mathrm{~h}$ after the start of consuming a diet containing $0.07 \mathrm{~g}$ acetic acid $/ 100 \mathrm{~g}$ diet (acetic acid group) or a diet without acetic acid (control group). For details of procedures, see p. 715.

$\dagger$ Mean values were significantly different from those of the control group at the same time-point $(P<0.05)$.

one or more of the following. The first is direct activation of GS, the second is enhancement of glucose transport/phosphorylation and the third is activation of gluconeogenesis or inhibition of glycolysis. We reported previously that acetic acid feeding after food deprivation does not induce the former two mechanisms but does induce the latter one (Fushimi et al. 2001). Together with lack of a difference in GS activity between the fed groups, the lower F-2,6- $\mathrm{P}_{2}$ in liver and the lower F-1,6- $\mathrm{P}_{2}-\mathrm{F}-6-\mathrm{P}$ ratios in skeletal muscle in the acetic acid group than in the control group might indicate that the enhancement of glycogen repletion by acetic acid feeding was due to the transitory induction of both the activation of gluconeogenesis and the inhibition of glycolysis.

Malonyl-CoA in liver, a potent allosteric inhibitor of carnitine palmitoyl-transferase I (McGarry \& Brown, 1997), was significantly lower in the acetic acid group than in the control group at $4 \mathrm{~h}$. Carnitine palmitoyl-transferase I, which controls the transfer of long-chain fatty acyl-CoAs into mitochondria where they are oxidized, is a rate-limiting enzyme of fatty acid oxidation. Hence, acetic acid feeding might induce the transient activation of fatty acid oxidation; in other words, the transient enhancement of fatty acid utilization in liver. Although acetate has been utilized as a substrate of lipogenesis in many cell studies, very little is known about the effect of dietary acetic acid on lipid metabolism. When acetate is metabolized by acetyl-CoA synthetase, AMP is simultaneously produced: acetate $+\mathrm{CoA}+\mathrm{ATP} \Leftrightarrow$ acetyl$\mathrm{CoA}+\mathrm{AMP}+$ pyrophosphate. Based on this point, it has been reported that in hepatocytes acetate activated AMP-activated protein kinase (Kawaguchi et al. 2002), the inhibitor of fatty acid and sterol synthesis (see review by Winder \& Hardie, 1999). The activation of AMP-activated protein kinase, which leads to the inhibition of acetyl-CoA carboxylase and the activation of malonyl-CoA decarboxylase, might induce the lower malonyl-CoA in the acetic acid group. Further the acetic acid group had a lower value of HMG-CoA, a substrate of cholesterol synthesis, at $4 \mathrm{~h}$ than the control group $(P<0.01)$. Therefore, the inhibition of lipogenesis by acetic acid feeding might be assumed to occur in liver through the activation of AMP-activated protein kinase.

Our results show that dietary acetic acid can enhance glycogen repletion, but does not induce supercompensation in both liver and skeletal muscle. The mechanism of this effect is different between liver and skeletal muscle. In liver, acetic acid feeding not only enhances glycogen repletion by transitory activation of gluconeogenesis and inhibition of glycolysis, but also simul- taneously enhances fatty acid utilization. In skeletal muscle, the enhancement of glycogen repletion by acetic acid feeding results from the inhibition of glycolysis without enhancement of fatty acid oxidation. Therefore, we conclude that supplementing meals with vinegar may be beneficial in not only the recovery of liver and skeletal muscle glycogen but also in enhancing fatty acid utilization in liver.

\section{Acknowledgements}

We thank Y. Oshima for technical suggestions, and Y. Kimura, N. Sugino, R. Sasaki and T. Kasuya for excellent technical assistance.

\section{References}

Carnona A, Mishima PT, Avery EH \& Freedland RA (1991) Time course changes in glycogen accretion, 6-phosphogluconate, fructose-2,6-bisphosphate, and lipogenesis upon refeeding a high sucrose diet to starved rats. Int $J$ Biochem 23, 455-460.

Casazza JP \& Veech RL (1986) The measurement of xylulose 5-phosphate, ribulose 5-phosphate, and combined sedoheptulose 7-phosphate and ribose 5-phosphate in liver tissue. Anal Biochem 159, 243-248.

Chang C, Ohshima T \& Koizumi C (1994) Changes in the composition of free amino acids, organic acids and lipids during processing and ripening of 'Hatahata-zushi', a fermented fish product of sandfish (Arctoscopus japonicus). J Sci Food Agric 66, 75-82.

Claus TH, El-Maghrabi MR, Regen DM, Stewart HB, McGrane M, Kountz PD, Nyfeles F, Pilkis J \& Pilkis SJ (1984) The role of fructose 2,6-bisphosphate in the regulation of carbohydrate metabolism. Curr Top Cell Regul 23, 57-86.

Dagley S (1974) Citrate UV spectrophotometric determination. In Methods of Enzymatic Analysis, pp. 1562-1565 [Ho Bergmeyel, editor]. New York: Academic Press.

DeBuysere MS \& Olson MS (1983) The analysis of acetyl-coenzyme A derivatives by reverse-phase high-performance liquid chromatography. Anal Biochem 133, 373-379.

El-Maghrabi MR, Claus TH, Piliks J, Fox E \& Piliks SJ (1982) Regulation of rat liver fructose 2,6-bisphosphatase. J Biol Chem 257, 7603-7607.

Fujii T, Sasaki T \& Okuzumi M (1992) Chemical composition and microbial flora of saba-narezushi (fermented mackerel with rice) (in Japanese). Nippon Suisan Gakkaishi 58, 891-894.

Fushimi T, Tayama K, Fukaya M, Kitakoshi K, Nakai N, Tsukamoto Y \& Sato Y (2001) Acetic acid feeding enhances glycogen repletion in liver and skeletal muscle of rats. J Nutr 131, 1973-1977. 
Fushimi T, Tayama K, Fukaya M, Kitakoshi K, Nakai N, Tsukamoto Y \& Sato Y (2002) The efficacy of acetic acid for glycogen repletion in rat skeletal muscle after exercise. Int J Sports Med 23, 218-222.

Hers HG \& Van Schaftingen E (1984) Protein phosphorylation in the control of glycolysis and gluconeogenesis in the liver. Adv Cyclic Nucleotide Protein Phosphorylation Res 17, 343-349.

Holloszy JO, Kohrt WM \& Hansen PA (1998) The regulation of carbohydrate and fat metabolism during and after exercise. Front Biosci 3, D1011-D1027.

Holness MJ, Schuster-Bruce MJ \& Sugden MC (1988) Skeletal-muscle glycogen synthesis during the starved-to-fed transition in the rat. Biochem J 254, 855-859.

Hue L, Sorbino F \& Bosca L (1984) Difference in glucose sensitivity of liver glycolysis and glycogen synthesis. Biochem $J$ 224, 779-786.

Kasamatsu T, Yoshimura N, Morioka S \& Hashimoto T (1996) Relationship of the number of consumed food items with nutritional status and obesity (in Japanese). Eiyougakuzasshi 54, 19-26.

Kawaguchi T, Osatomi K, Yamashita H, Kabashima T \& Uyeda K (2002) Mechanism for fatty acid 'sparing' effect on glucose-induced transcription. J Biol Chem 277, 3829-3835.

Kuwajima M, Newgard CB, Foster DW \& McGarry JD (1984) Time course and significance of changes in hepatic fructose-2,6-bisphosphate levels during refeeding of fasted rats. J Clin Invest 74, 1108-1111.

Liu YQ \& Uyeda K (1996) A mechanism for fatty acid inhibition of glucose utilization in liver. $J$ Biol Chem 271, 8824-8830.

Lo S, Russell JC \& Taylor AW (1970) Determination of glycogen in small tissue samples. J Appl Physiol 28, 234-236.

Lowry OH \& Passonneau JV (editors) (1972) A collection of metabolite analysis. In A Flexible System of Enzymatic Analysis, pp. 146-218.

McGarry JD \& Brown NF (1997) The mitochondrial carnitine palmitoyltransferase system. From concept to molecular analysis. Eur J Biochem 244, 1-14.

McGarry JD, Kuwajima M, Newgard CB \& Foster DW (1987) From dietary glucose to liver glycogen: the full circle round. Ann Rev Nutr 7, 51-73.

Mine H, Yamagami Y \& Ohno N (1982) Studies in food seasoning (part 3) 'Takikomi-zushi' (in Japanese). Rep Res Matsuyama Shinonome Jr Coll 13, 81-88

Murase M, Kimura Y \& Nagata Y (1995) Determination of portal shortchain fatty acids in rats fed various dietary fibers by capillary gas chromatography. J Chromatogr B 664, 415-420.

Nishimura M \& Uyeda K (1995) Purification and characterization of a novel xylulose 5-phosphate-activated protein phosphatase catalyzing dephosphorylation of fructose-6-phosphate,2-kinase:fructose-2,6bisphosphatase. J Biol Chem 270, 26341-26346.

Okuda K \& Hayashi K (1994) Validity and limit of dietary guideline 'try to take 30 kinds of food a day' (in Japanese). Konan Women's Univ Kennkyu Kiyo 31, 255-266.

Passonneau JV \& Lowry OH (editors) (1993) Glycogen synthase. In Enzymatic Analysis: A Practical Guide, pp. 268-269. Totowa, NJ: Humana Press.

Pomare EW, Branch WJ \& Cummings JH (1985) Carbohydrate fermentation in the human colon and its relation to acetate concentrations in venous blood. J Clin Invest 75, 1448-1454.

Ren H, Endo H, Watanabe E \& Hayashi T (1997) Chemical and sensory characteristics of Chinese, Korean and Japanese vinegars. J Tokyo Univ Fisheries 84, 1-11.

Rodger G, Hastings R, Cryne C \& Bailey J (1984) Diffusion properties of salt and acetic acid into herring and their subsequent effect on the muscle tissue. J Food Sci 49, 714-720.

Ross BD \& Krebs HA (1967) Carbohydrate metabolism of the perfused rat liver. Biochem J 105, 869-875.

Seitz HJ, Müller MJ \& Nordmeyer P (1976) Concentration of cyclic AMP in rat liver as a function of the insulin/glucagon ratio in blood under standardized physiological conditions. Endocrinology 99, $1313-1318$

Seus I \& Martin M (1993) The influence of marinating with food acids on the composition and sensory properties of beef. Fleischwirtsch 73, $292-295$.

Shimbo S, Kimura K, Imai Y, Yasumoto M, Yamamoto K, Watanabe T, Iwami O, Ikeda M \& Nakatsuka H (1994) Number of food items as an indicator of nutrient intake. Ecol Food Nutr 32, 197-206.

Struck E \& Ashmore J (1966) Wieland O Effects of glucagons and long chain fatty acids on glucose production by isolated perfused rat liver. Adv Enzyme Regul 4, 219-224.

Uyeda K, Furuya E \& Richards CS (1982) Yokoyama M Fructose2,6-P2, chemistry and biological function. Mol Cell Biochem 48, $97-120$.

Wakelam MJO \& Pette D (1982) The control of glucose 1,6-phosphate by developmental state and hormonal stimulation in culutured muscle tissue. Biochem J 204, 765-769.

Williamson JR \& Krebs HA (1961) Acetoacetate as fuel of respiration in the perfused rat heart. Biochem J 80, 540-547.

Winder WW \& Hardie DG (1999) AMP-activated protein kinase, a metabolic master switch: possible roles in Type 2 diabetes. Am J Physiol 277, E1-E10. 